\title{
Tidal and Groundwater Fluxes to a Shallow, Microtidal Estuary: Constraining Inputs Through Field Observations and Hydrodynamic Modeling
}

\author{
Neil K. Ganju • Melanie Hayn • Shih-Nan Chen • \\ Robert W. Howarth • Patrick J. Dickhudt • \\ Alfredo L. Aretxabaleta • Roxanne Marino
}

Received: 18 November 2011 / Revised: 22 March 2012 / Accepted: 9 May 2012 / Published online: 30 May 2012

(C) Coastal and Estuarine Research Federation (outside the USA) 2012

\begin{abstract}
Increased nutrient loading to estuaries has led to eutrophication, degraded water quality, and ecological transformations. Quantifying nutrient loads in systems with significant groundwater input can be difficult due to the challenge of measuring groundwater fluxes. We quantified tidal and freshwater fluxes over an 8-week period at the entrance of West Falmouth Harbor, Massachusetts, a eutrophic, groundwater-fed estuary. Fluxes were estimated from velocity and salinity measurements and a total exchange flow (TEF) methodology. Intermittent cross-sectional measurements of velocity and salinity were used to convert point measurements to cross-sectionally averaged values over the entire deployment (index relationships). The estimated mean freshwater flux $\left(0.19 \mathrm{~m}^{3} / \mathrm{s}\right)$ for the 8 -week period was mainly due to groundwater input $\left(0.21 \mathrm{~m}^{3} / \mathrm{s}\right)$ with contributions from precipitation to the estuary surface $\left(0.026 \mathrm{~m}^{3} / \mathrm{s}\right)$ and removal by evaporation $\left(0.048 \mathrm{~m}^{3} / \mathrm{s}\right)$. Spring-neap variations in freshwater export that appeared in shorter-term averages were mostly artifacts of the index relationships. Hydrodynamic modeling with steady groundwater input demonstrated that while the TEF methodology
\end{abstract}

N. K. Ganju $(\bowtie) \cdot$ P. J. Dickhudt • A. L. Aretxabaleta

U.S. Geological Survey, Woods Hole Coastal and Marine Science

Center,

384 Woods Hole Road,

Woods Hole, MA 02543, USA

e-mail:nganju@usgs.gov

M. Hayn · R. W. Howarth · R. Marino

Department of Ecology and Evolutionary Biology, Cornell

University,

Ithaca, NY, USA

S.-N. Chen

National Taiwan University, Institute of Oceanography,

Taipei, Taiwan resolves the freshwater flux signal, calibration of the indexsalinity relationships during spring tide conditions only was responsible for most of the spring-neap signal. The mean freshwater flux over the entire period estimated from the combination of the index-velocity, index-salinity, and TEF calculations were consistent with the model, suggesting that this methodology is a reliable way of estimating freshwater fluxes in the estuary over timescales greater than the springneap cycle. Combining this type of field campaign with hydrodynamic modeling provides guidance for estimating both magnitude of groundwater input and estuarine storage of freshwater and sets the stage for robust estimation of the nutrient load in groundwater.

Keywords Estuarine hydrodynamics - Coastal groundwater discharge $\cdot$ Total exchange flow $\cdot$ Estuarine modeling $\cdot$ Indexvelocity method

\section{Introduction}

Impact of Groundwater Fluxes to Estuaries

The past few decades have seen a massive increase in eutrophication of estuaries globally, leading to widespread hypoxia and anoxia, habitat degradation, alteration of foodweb structure, loss of biodiversity, and increased frequency, spatial extent, and duration of harmful algal blooms (NRC 2000; Boesch 2002; Howarth 2008). A majority of estuaries in the USA are degraded as a result (Bricker et al. 2007). Shallow seagrass-dominated lagoons appear to be particularly sensitive (Nixon et al. 2001; McGlathery et al. 2007). In many of these ecosystems, endemic species such as seagrass are lost as benthic algae and phytoplankton 
dominate under increased nutrient supply. Estimating past, current, and future nutrient loads is critical for evaluating ecological response to land-use changes. Regulatory agencies often use load criteria to manage estuarine water quality, therefore accurate estimation of nutrient loads is critical. At the most fundamental level, this requires estimation of freshwater flux to the estuary.

Though many eutrophic estuaries receive the majority of their freshwater and nutrient loads from rivers, coastal groundwater discharge can be a dominant source in some systems. Valiela et al. (1990) noted the importance of coastal groundwater discharge to New England coastal bays in terms of nitrogen load. Kroeger et al. (2007) found that submarine groundwater discharge accounted for up to $33 \%$ of the freshwater discharge and $50 \%$ of nutrient loads in Tampa Bay. Several methods to measure fresh coastal groundwater discharge have been used with varying success dependent on the system and the assumptions. These include radiochemical tracer methods (e.g., Moore 1996; Cable et al. 1996), seepage meters (Lee 1977), eddy correlation (Crusius et al. 2008), thermal imaging (Portnoy et al. 1998), and watershed mass balance of water (Kroeger et al. 2006). In all these cases, estimating a whole-system fresh coastal groundwater discharge over sub-annual timescales may be confounded by temporal and spatial variability. A need exists for robust methods to estimate the fresh portion of coastal groundwater discharge (and associated nutrient loads) to estuarine and coastal systems.

\section{Quantification of Tidal Water Fluxes and Total Exchange Flow Through Estuarine Cross-sections}

Quantifying tidal water fluxes through estuarine crosssections can be achieved using a variety of methods. Straightforward volume calculations at tidal timescales using detailed intertidal bathymetry and tidal water level data can yield water fluxes; this method requires accurate bathymetry, complete coverage of tidally affected areas, and relies on the assumption of a spatially uniform water level at any given time. In more complicated situations, such as tidal channel networks or very large estuaries, acoustic technologies have become the standard measurement method. Simpson and Oltmann (1993) and Simpson and Bland (2000) first detailed the use of shipboard acoustic Doppler current profilers (ADCPs) to calculate tidally varying discharge in estuarine channels; Ruhl and Simpson (2005) further described methods to generate continuous timeseries of tidal water fluxes in tidal channels. While these methods are accurate for instantaneous tidal water fluxes, extracting the residual flux due to freshwater flux alone can be difficult because of the small ratio of freshwater flux to instantaneous tidal flux (Ganju and Schoellhamer 2006). However, tidal water fluxes along with concurrent salinity measurements can be used to estimate estuarine total exchange flow (TEF; MacCready 2011), which provides a different avenue for estimating freshwater flux. MacCready (2011) used an isohaline coordinate system to describe estuarine exchange flows. This analysis tracks the transformation of water masses as they enter and exit the estuary due to tidal processes, using salinity as the conservative tracer. The net transport of water over a tidal cycle (or any period), in salinity space, is the TEF. The terms in the TEF analysis can be used in Knudsen's (1900) salt balance, yielding a solution for freshwater flux.

Ganju (2011) combined tidal water flux measurements following Ruhl and Simpson (2005) with a time-dependent Knudsen balance to estimate mean and time-varying groundwater flux in a small landward tidal channel of West Falmouth Harbor, Massachusetts. Because of the landward location of this site, the influence of precipitation, evaporation, and estuarine storage were negligible. Measurements at the harbor entrance however, must be reconciled with potentially high rates of precipitation and evaporation over the estuarine surface, as well as temporal changes in flushing (which can affect storage of freshwater within the estuary). The harbor has experienced rapid eutrophication and habitat degradation due to the input of nitrate-rich groundwater from a contaminated aquifer. In this study, we detail a field campaign aimed at quantifying the total groundwater flux to the entire harbor, which is mainly supplied via shoreline seeps. We first describe the relevant characteristics of the harbor, followed by methods to calculate continuous tidal water flux, mean salinity, precipitation, and evaporation. The isohaline analysis is used to estimate mean and timevarying freshwater flux at the harbor mouth. A threedimensional hydrodynamic model is used to verify the application of the isohaline analysis and the mechanisms that control the time-varying nature of the freshwater flux.

\section{Site Description}

\section{Watershed Description}

West Falmouth Harbor lies on the western shore of upper Cape Cod, Massachusetts, on the eastern side of Buzzards Bay (Fig. 1). Cape Cod is a glacially carved land feature, with a prominent moraine deposit running in the north-south direction on the western side. The Sagamore lens of the underlying aquifer is characterized by a water table high-centered 13-km northeast of West Falmouth Harbor. Moraine deposits are considered to have greater substrate variability than outwash deposits, which are more common on the south side of upper Cape Cod. Annual precipitation over upper Cape Cod averaged $1.24 \mathrm{~m} /$ year during the 1997-2010 period with a relatively stable annual distribution. There are few prominent 
Fig. 1 West Falmouth Harbor and site locations. Dashed line indicates transects for crosssectional tidal-cycle surveys; solid lines are groundwater watershed drainage delineations from Kroeger et al. (2006). Falmouth Wastewater Treatment Plant $(F W T P)$ is less than $1 \mathrm{~km}$ east of map edge. Depth contours are in meters. $A D C P$ acoustic Doppler current profiler, $A V M$ acoustic velocity meter

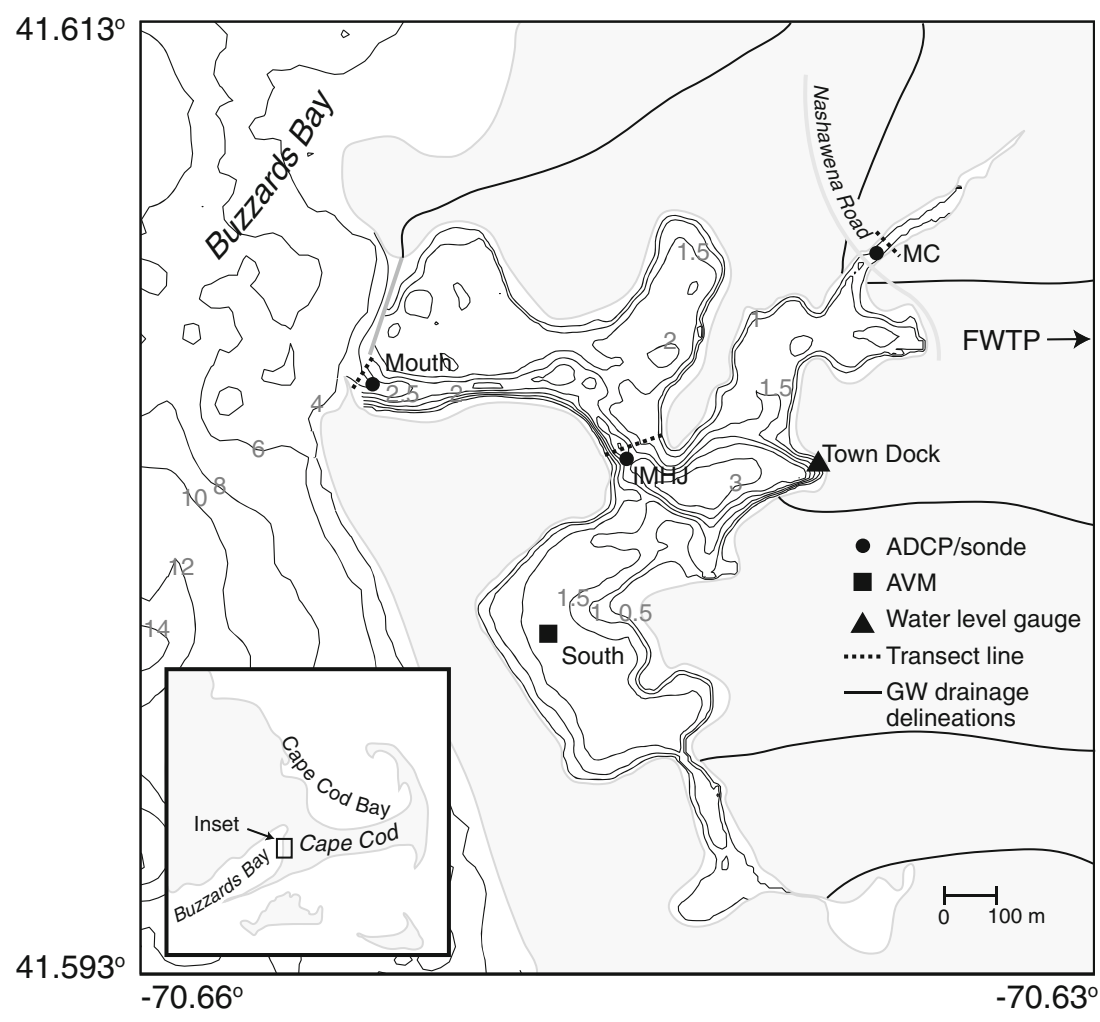

rivers on Cape Cod; the majority of freshwater discharge to the coast occurs as either direct groundwater discharge or groundwater discharge to small streams (LeBlanc et al. 1986). Recent delineation of watershed boundaries indicates that West Falmouth Harbor's watershed is approximately $6.7 \mathrm{~km}^{2}$ (Howes et al. 2006).

\section{Estuarine Description}

West Falmouth Harbor has a surface area of approximately $0.7 \mathrm{~km}^{2}$ and a mean depth of slightly more than $1 \mathrm{~m}$. The outer embayment of the harbor is connected to Buzzards Bay via a 3-m deep, 150-m wide channel constrained by rock jetties on both sides. The outer embayment is connected to the inner embayments through a 3-m deep, 150-m wide channel bounded by a sand beach on the west and rocky/ hardened shoreline on the east. Portions of the harbor are bordered by intertidal mudflats and wetlands. In many of the intertidal areas groundwater can be observed entering the estuarine surface at low tide. The tide in West Falmouth Harbor is essentially a standing wave, with a 1.9-m range during spring tides and a $0.7-\mathrm{m}$ range during neap tides at the harbor entrance. Mean tidal currents at the mouth approach $0.5 \mathrm{~m} / \mathrm{s}$. Buzzards Bay provides salt to West Falmouth Harbor on flood tide, and salinity typically ranges between 30 and 32 during summer months. Subtidal variations in Buzzards Bay salinity are typically larger than tidal-timescale variations (Ganju et al. 2011).
We occupied five sites during summer 2010: (1) site Mouth, (2) site IMHJ, (3) site MC, (4) site South, and (5) site Town Dock. Site Mouth was located on the bed of the entrance channel to the harbor on a sand bed in approximately $3 \mathrm{~m}$ of water. Site IMHJ was located on the west side of the sandy main channel adjacent to a dense eelgrass meadow on the east side of the channel, at a depth of $3 \mathrm{~m}$. Site MC was in Mashapaquit Creek landward of the Nashawena Road bridge, and is discussed in detail by Ganju (2011). Site South was located in the south embayment of the harbor at a depth of $1.5 \mathrm{~m}$. Site Town Dock was located at the West Falmouth Harbor Town Dock. In this study, freshwater flux estimates were made at the two cross-sections at sites Mouth and IMHJ. Freshwater fluxes from site MC were detailed by Ganju (2011) and are not covered in this paper. Velocity data from site South are used for tidal harmonic analyses, and water level data from site Town Dock are used to compute estuary volume (discussed below).

\section{Methods}

Continuous Tidal Water Fluxes: Index-Velocity Method

A proxy for a continuous record of water fluxes in tidally affected channels can be constructed from an index velocity $\left(v_{\mathrm{i}}\right)$ and water level $(h)$, and a less-frequent record of crosssectionally averaged velocity $\left(v_{\mathrm{ca}}\right)$ and channel area $(A)$ over 
some representative period (Ruhl and Simpson 2005). A complete record of $v_{\mathrm{ca}}$ is computed using the correlation between $v_{\mathrm{i}}$ and $v_{\mathrm{ca}}$, and a complete record of $A$ is computed using $h$ and the channel geometry. The product of $v_{\mathrm{ca}}$ and $A$ from the complete record yields a continuous record of tidal water fluxes $\left(Q_{\mathrm{i}}\right)$.

At all sites (excluding site South and Town Dock), we deployed a Nortek Aquadopp ADCP and a Sea-Bird 39 pressure/temperature (PT) sensor approximately $0.1 \mathrm{mab}$ to measure $v_{\mathrm{i}}$ and $h$, respectively. At site Mouth the package was located in the center of the entrance channel. At site IMHJ the package was deployed on the west side of the channel due to heavy eelgrass coverage on the east side of the channel. At site MC the package was deployed in the center of the channel landward of the Nashawena Road bridge. All instruments sampled at 5-min intervals, and the ADCPs sampled in $0.5 \mathrm{~m}$ bins. At site South, an Aanderaa RCM acoustic velocity meter (AVM) was deployed on the bed, sampling in 5-min intervals.

Measurements of $v_{\mathrm{ca}}$ and $A$ were collected using a RD Instruments $1,200 \mathrm{kHz}$ Rio Grande ADCP in downwardlooking configuration. At sites Mouth and IMHJ the ADCP was deployed from a $16 \mathrm{ft}$ shallow-draft vessel with the ADCP transducer approximately $0.25 \mathrm{~m}$ below the water surface and differential GPS used to track boat movement relative to the bed. At site MC the ADCP was deployed from an Oceanscience River Surveyor catamaran with radio modems and a tagline secured from bank-to-bank. Those measurements are discussed by Ganju (2011) and are not shown in this study. At all sites USGS protocols (Mueller and Wagner 2009) were followed for ADCP settings, compass calibration, and edge estimates (due to the inability to measure near banks). The surveys were performed during spring tides (Table 1) when the largest range of conditions was expected.

\section{Continuous Tidal Water Fluxes: Volumetric Change Method}

Water fluxes estimated using the index-velocity method have previously been compared with independent water flux measurements in riverine environments (Costa et al. 2006). We attempt an independent measure at the mouth of West Falmouth Harbor using the change in volume of the entire harbor on tidal timescales. A general model for this approach can be summarized as

$\frac{\mathrm{d} V}{\mathrm{~d} t}=Q_{\mathrm{v}}+P+G-E$

where $V$ is harbor volume, $Q_{\mathrm{v}}$ is water flux at the mouth (flood positive), $G$ is incoming groundwater flux, $P$ is precipitation, and $E$ is evaporation. Assuming that $Q_{\mathrm{v}}$ is several orders of magnitude greater than $P, G$, and $E$, reduces this to

$\frac{\mathrm{d} V}{\mathrm{~d} t}=Q_{\mathrm{v}}$

If we further assume that the tide in the harbor behaves as a standing wave with minimal lag between embayments, we can calculate harbor volume with detailed bathymetry and water level measurements from site Town Dock (Fig. 1).

We used a Trimble AgGPS Model 132 DGPS with Omnistar beacon to provide sub-meter accuracy horizontal coordinates, and an ODEC Bathy500MF precision survey fathometer utilizing a $200 \mathrm{kHz}, 3^{\circ}$ beam transducer to provide soundings at a rate of $5-10 \mathrm{~Hz}$. The shallow intertidal area was surveyed on foot using a survey staff. The sounding data were processed to generate a bathymetric grid at a 5-m horizontal resolution. We calculated the harbor volume at water levels between lowest low tide and highest high tide and fit a regression to the data ( $p$ value of $<0.00001$ ). Water level measurements were collected at 5-min intervals with a Global Water WL16 vented, pressure and temperature compensated water level logger (accurate to $0.009 \mathrm{~m}$ ), deployed at site Town Dock (Fig. 1). The regression between water level and volume was used to calculate harbor volume; $Q_{\mathrm{v}}$ was calculated as

$Q_{\mathrm{v}}\left(t_{1.5}\right)=\frac{V_{2}-V_{1}}{t_{2}-t_{1}}$

where $Q_{\mathrm{v}}\left(t_{1.5}\right)$ is the tidal water flux at the middle of the water level measurement interval.

Continuous Mean Salinity: Index-Salinity Method

Similarly to the estimation of tidal water fluxes, a proxy for a continuous record of mean salinity can be constructed
Table 1 Deployment and $\mathrm{ADCP} /$ salinity survey dates

\begin{tabular}{llllc}
\hline Site & Deployment dates & $\begin{array}{l}\text { ADCP/salinity } \\
\text { survey dates }\end{array}$ & $\begin{array}{l}\text { Number } \\
\text { of ADCP } \\
\text { transects }\end{array}$ & $\begin{array}{l}\text { Number of salinity } \\
\text { profile sets } \\
\text { (5 profiles/set) }\end{array}$ \\
\hline Mouth & 2 July to 9 September 2010 & 9 and 26 August 2010 & 143 & 12 \\
IMHJ & 2 July to 9 September 2010 & 10 and 26 August 2010 & 78 & 10 \\
MC & 22 July to 9 September 2010 & 11 August 2010 & 70 & 12 \\
\hline
\end{tabular}


from an index-salinity measurement $\left(s_{\mathrm{i}}\right)$ and a less-frequent measurement of cross-sectionally averaged salinity $\left(s_{\mathrm{ca}}\right)$ over some representative time period; the correlation between the two can be used to estimate continuous crosssectionally averaged salinity. At sites Mouth and IMHJ, a YSI 6-series multi-parameter sonde was deployed $0.3 \mathrm{mab}$ adjacent to the ADCP/PT package on a pedestal mount anchored by a $50-\mathrm{kg}$ lead weight. At site $\mathrm{MC}$ a vertical array of conductivity/temperature sensors was deployed as detailed by Ganju (2011).

The multi-parameter sondes were downloaded and serviced weekly. At the near-bed sites (Mouth and IMHJ) we retrieved the sondes from the fixed mounts and serviced them simultaneously on the dock near the mouth of the harbor. Servicing consisted of pre- and post-cleaning fouling checks, battery replacement, data download, and checks with known conductivity standards. Servicing guidelines, fouling corrections, and drift corrections were applied following the guidelines of Wagner et al. (2006).

Cross-sectionally averaged salinity at all sites was estimated by vertical profiling with a multi-parameter sonde at five equally spaced locations at each cross-section. The sonde sampled at $1 \mathrm{~Hz}$ and downcast data were interpolated to a uniform vertical coordinate, weighted by total depth of the profile, and averaged. Profiles were collected intermittently during the ADCP surveys (Table 1).

\section{Freshwater Flux at Mouth}

MacCready (2011) presents the calculation of the estuarine TEF using isohaline coordinates as:

$\left.Q_{\text {in }} \equiv \int \frac{-\partial Q}{\partial s}\right|_{\text {in }} \mathrm{d} s ;\left.Q_{\text {out }} \equiv \int \frac{-\partial Q}{\partial s}\right|_{\text {out }} \mathrm{d} s$

where $Q$ is the tidal water flux and $s$ is salinity. These quantities are practically computed by sorting tidal water fluxes by salinity, and summing transport over discrete salinity bins to yield a net incoming $\left(Q_{\text {in }}\right)$ and outgoing $\left(Q_{\text {out }}\right)$ transport in salinity space. This method attempts to track the transformation of water masses as they enter and exit the estuary; therefore a parcel of water entering at a salinity at 30 , and exiting at the same salinity yields no exchange flow.

The salt fluxes due to TEF are

$\left.F_{\text {in }} \equiv \int s \frac{-\partial Q}{\partial s}\right|_{\text {in }} \mathrm{d} s ;\left.F_{\text {out }} \equiv \int s \frac{-\partial Q}{\partial s}\right|_{\text {out }} \mathrm{d} s$

and flux-weighted salinity is defined as:

$s_{\text {in }} \equiv \frac{F_{\text {in }}}{Q_{\text {in }}} ; s_{\text {out }} \equiv \frac{F_{\text {out }}}{Q_{\text {out }}}$

As shown by MacCready (2011), enforcing mass and volume conservation in TEF terms yields a TEF version of the Knudsen (1900) relationship that is derived without assuming steady, two-layer flow:

$Q_{\text {in }}=\frac{s_{\text {out }}}{\Delta s} Q_{R}+\frac{1}{\Delta s} \frac{\mathrm{d}}{\mathrm{d} t} \int s \mathrm{~d} V ;$

$-Q_{\text {out }}=\frac{s_{\text {in }}}{\Delta s} Q_{R}+\frac{1}{\Delta s} \frac{\mathrm{d}}{\mathrm{d} t} \int s \mathrm{~d} V$

where $Q_{\mathrm{R}}$ is freshwater flux, $\Delta s$ is $s_{\text {in }}-s_{\text {out }}$, and $V$ is estuary volume; the last term accounts for salt storage in the estuary. These can be inverted to solve for freshwater flux as

$Q_{R}=\frac{\Delta s}{s_{\text {out }}} Q_{\text {in }}-\frac{1}{s_{\text {out }}} \frac{\mathrm{d}}{\mathrm{d} t} \int s \mathrm{~d} V ;$

$Q_{R}=-\frac{\Delta s}{s_{\text {in }}} Q_{\text {out }}-\frac{1}{s_{\text {in }}} \frac{\mathrm{d}}{\mathrm{d} t} \int s \mathrm{~d} V$

We performed the TEF calculations over the entire period and in 120-h moving windows to extract the mean and timevarying freshwater flux signal at the mouth of the estuary ignoring subtidal changes in salt storage (last term on the rhs of Eq. 8). We used a salinity bin size of 0.1 psu over the 0 35 psu range. For each time interval in the 120 -h window, we assign the water transport value into the corresponding salinity bin (separately for flood and ebb directions), thereby filling two matrices in time and salinity space with the sum of the transport values in a given class at a given time, for flood and ebb tide. The temporal mean over salinity space then gives the gross transports on flood and ebb; the sum of these gives the net transport in salinity space ( $Q_{\text {in }}$ and $Q_{\text {out }}$, Eq. 4$)$. The ensuing calculations are performed with these quantities.

We use the cross-sectionally averaged salinity data from sites Mouth and IMHJ and compared three sets of tidal water flux data at site Mouth (one set at site IMHJ): (1) index-velocity based with a linear fit, (2) index-velocity based with a quadratic fit, and (3) volumetric-change based. In the three-dimensional modeling context presented by MacCready (2011), the analysis is applied to individual cells in the lateral and vertical direction across the twodimensional cross-section; with this set of field data we apply the analysis in a zero-dimensional sense (the whole cross-section is treated as one point). The freshwater flux at the mouth will include contributions from groundwater discharge, direct precipitation to the estuary, and removal due to evaporation. It will also retain any signal due to subtidal salt storage within the estuary or estuarine sediments.

\section{Precipitation and Evaporation}

Precipitation data were retrieved from the NCEP/EMC precipitation database, which consists of daily, gage-based reports (http://data.eol.ucar.edu/codiac/dss/id=21.005), for stations FMH (Falmouth, MA; $11 \mathrm{~km}$ NE of West Falmouth Harbor) and HYA (Hyannis, MA; $30 \mathrm{~km} \mathrm{E}$ of West 
Falmouth Harbor). The daily precipitation record was multiplied by the surface area of the harbor $\left(0.7 \mathrm{~km}^{2}\right)$ and converted to a volumetric water flux rate to compare with freshwater flux estimates. We calculated evaporation using the classic Penman approach for open water systems (Penman 1948; Dunne and Leopold 1978; Shuttleworth 1993). Input data were either directly measured (water temperature), or obtained from the Woods Hole Oceanographic Institution (solar irradiance and $\mathrm{max} / \mathrm{min}$ air temperature; http://cis.whoi.edu/ science/PO/climate/index.cfm) and the Northeast Regional Climate Center (average air temperature, dew point, and wind speed; http://www.nrcc.cornell.edu). Evaporation estimates were applied to the harbor surface area to yield a water flux value.

\section{Results}

\section{Continuous Tidal Water Fluxes: Index Velocity Method}

Continuous time-series of velocity $\left(v_{\mathrm{i}}\right)$ were obtained at all sites. At site Mouth peak velocities ranged from $0.50 \mathrm{~m} / \mathrm{s}$ on spring tides to $0.25 \mathrm{~m} / \mathrm{s}$ on neap tides. During spring tides $(9$ and 27 August 2010), we collected 143 ADCP transects. We measured channel area $(A)$ and geometry at high tide and cross-sectionally averaged velocity $\left(v_{\mathrm{ca}}\right)$ from slack after high tide to the following slack after high tide (0700 to 2000 UTC on 9 August 2010; additional measurements made from 1200 to 1400 UTC on 27 August 2010). At site IMHJ peak velocities ranged from $0.40 \mathrm{~m} / \mathrm{s}$ on spring tides to $0.20 \mathrm{~m} / \mathrm{s}$ on neap tides. During spring tides (10 and 27 August 2010) we collected 78 ADCP transects, successfully measuring channel area and geometry at high tide and crosssectionally averaged velocity from slack after high tide to the following slack after high tide (0730 to 2030 UTC on 9 August 2010; additional measurements made from 1200 to 1400 UTC on 27 August 2010). Continuous water level measurements were obtained at all sites.

The index velocity calibration at site Mouth was developed using the velocity from the first (near-bed) bin of the Aquadopp as the index velocity $v_{\mathrm{i}}$ and the cross-sectional ADCP measurements for $v_{\mathrm{ca}}$ (Fig. 2). As a sensitivity test, we obtained both a quadratic and linear calibration function to determine how the index velocity calibration affects the computation of freshwater flux (below). In terms of site characterization, the relationship between the index velocity and cross-sectionally averaged velocity suggests that the site is flood dominant (i.e., $v_{\mathrm{i}}>v_{\mathrm{ca}}$ on flood tide and $v_{\mathrm{i}}<v_{\mathrm{ca}}$ on ebb tide) and is likely centered on the flood tide jet. At site IMHJ the index velocity calibration was developed using the velocity from the first bin of the Aquadopp as the index velocity $v_{\mathrm{i}}$ on flood tide and the third bin of the ADCP as the index velocity on ebb tide, and the cross-sectional measurements for $v_{\text {ca }}$ (Fig. 3). Index-velocity relationships using the same bin for $v_{\mathrm{i}}$ on flood and ebb tide at site IMHJ led to poor correlation. This suggests that the location of site IMHJ was not optimal for the index velocity measurement. It is likely that both channel asymmetry and the geometry of the harbor are responsible for a complex index-velocity relationship. Channel cross-sections were measured with the ADCP at both sites during slack high water. Relationships between water level and cross-sectional area were determined with the AreaComp program, provided by the USGS Office of Surface Water's Hydroacoustics
Fig. 2 Index velocity calibrations for site Mouth. Both a quadratic and linear calibration were applied to investigate sensitivity of TEF calculation to calibration choice

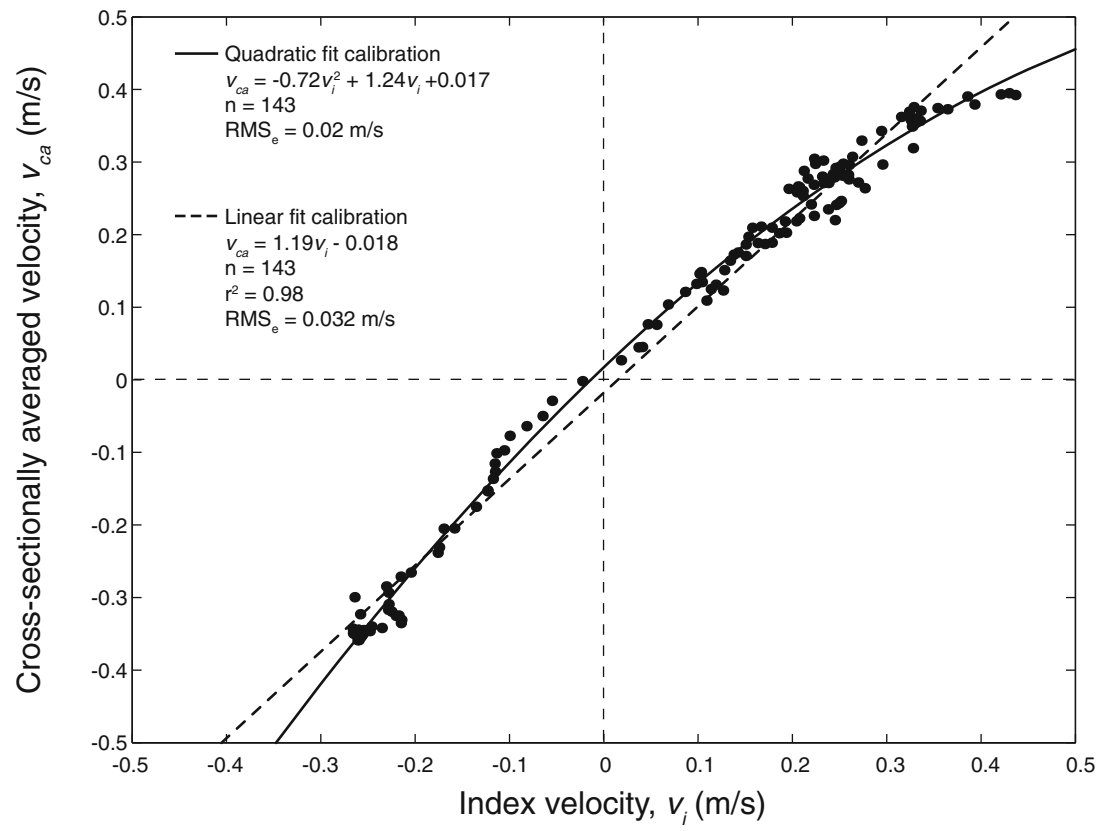


Fig. 3 Index velocity calibration for site IMHJ

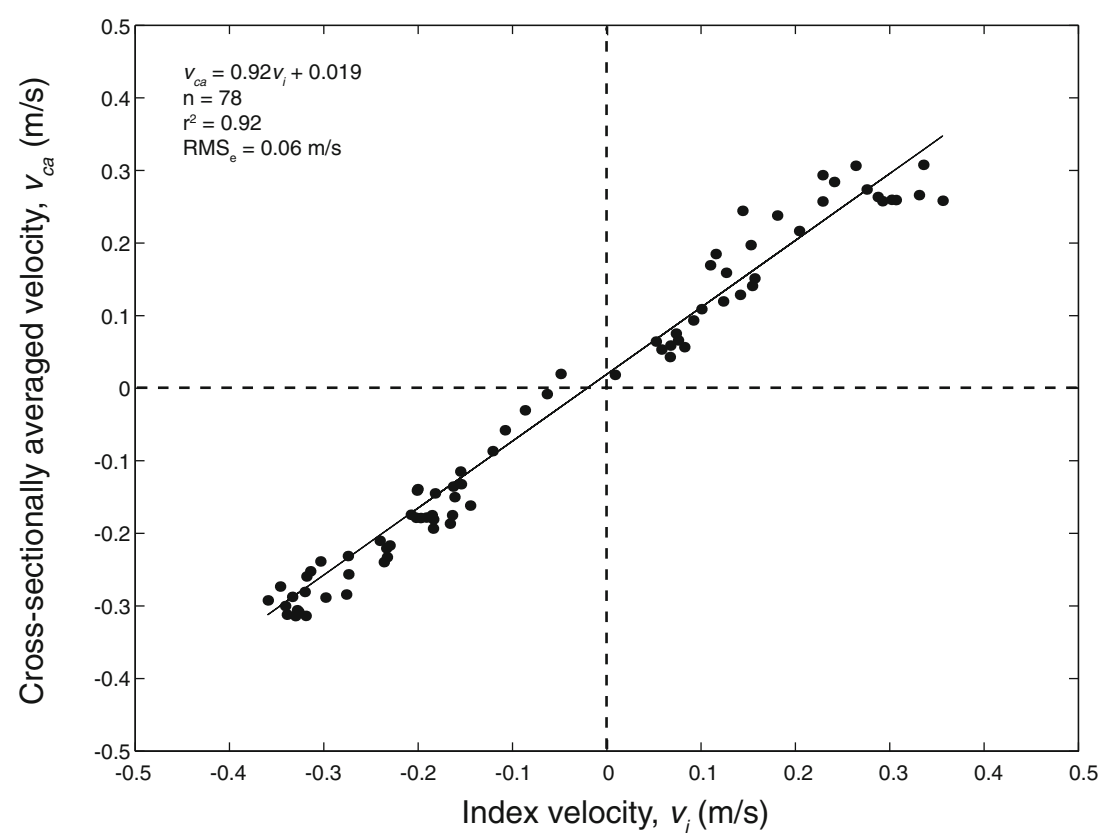

Workgroup (http://hydroacoustics.usgs.gov). The tidal water flux time series at both sites (Fig. 4) were calculated as the product of $v_{\text {ca }}$ and $A$. Peak tidal water fluxes at site Mouth were over $100 \mathrm{~m}^{3} / \mathrm{s}$ on spring tides, and $50 \mathrm{~m}^{3} / \mathrm{s}$ on neap tides. Peak tidal water fluxes at site IMHJ were smaller by approximately $20 \%$.
Fig. 4 Time series of $A$ water level, $B$ precipitation and evaporation over the estuary surface, $C$ tidal water flux at sites Mouth and IMHJ, $D$ crosssectionally averaged salinity at sites Mouth and IMHJ, and $E$ calculated freshwater flux at sites Mouth and IMHJ

Tidal Water Fluxes: Comparison with Volume Change Method

The tidal water flux estimates derived from the indexvelocity method compare well with the independent measurement based on changes in water depth and volume in the harbor (Fig. 5), at both tidal timescales and when applied to the isohaline analysis. The volumetric change method assumes that changes in tidal level throughout the harbor are completely in phase. Harmonic analysis of water level and ADCP velocities was performed using the MATLAB code T_TIDE (Pawlowicz et al. 2002). As expected the predominant tidal constituent is $M_{2}(83.1 \%$ of total water level variance), with small contributions from $N_{2}(6.9 \%), S_{2}$ $(4.1 \%), K_{1}(1.1 \%)$, and $O_{1}(0.7 \%)$, with the nonlinear component $M_{4}(2.1 \%)$ being especially significant in the shallower sites. The water level phase difference between the sites is on the order of 5 min for both diurnal and semidiurnal tidal components. The velocity phase differences between sites for each ADCP bin are slightly larger especially near-bottom due to frictional effects. When the depth-average velocity is analyzed, the phase lags show a better agreement with the water level phase values.

\section{Continuous Mean Salinity: Index-Salinity Method}

Continuous index salinity measurements were made at all sites, with fouling shifts and corrections applied following Wagner et al. (2006). Index salinity varied between 30 and 32 psu at both site Mouth and IMHJ. Site Mouth experienced very little fouling or spurious data; at site IMHJ there were numerous spurious spikes and short periods $(<1 \mathrm{~h})$ of wide fluctuation; these are likely associated with lateral advection of unmixed water masses (i.e., fronts) from the northeast and southern portions of the harbor. The time series of water temperature shows concurrent fluctuations.

Vertical profiles of salinity at five lateral positions in the channel were obtained at all sites. At site Mouth 12 sets of profiles were collected during a spring tide (9 August 2010) while ten sets were collected at site IMHJ on 10 August 2010. Lateral variability in near-surface salinity at site IMHJ (standard deviation $=0.61 \mathrm{psu}$ ) was twice as high as site Mouth (0.32 psu). Maximum vertical stratification at site IMHJ ( $1 \mathrm{psu} / \mathrm{m})$ was over twice as high as site Mouth $(0.4 \mathrm{psu} / \mathrm{m})$. This variability manifests itself in the index salinity relationships (Fig. 6): the slope of the curve at site Mouth is close to unity while at site IMHJ the slope is close to 2. At site IMHJ the index-salinity location was biased towards a saltier portion of the channel both laterally and vertically (hence the large slope). As with the velocities, the index salinities at site Mouth better-represented the measured cross-sectionally averaged salinity.

\section{Freshwater Flux}

The continuous time series of tidal water flux and crosssectionally averaged salinity (Fig. 4C and D, respectively) were used in the TEF analysis to calculate freshwater flux. At site Mouth, mean freshwater flux over the deployment period was $0.19 \mathrm{~m}^{3} / \mathrm{s}$ using the index-velocity tidal water flux data, and $0.18 \mathrm{~m}^{3} / \mathrm{s}$ using the volumetric change data. Index-velocity calibration choice (linear vs. quadratic) made
Fig. 5 Comparison of instantaneous (5-min interval) tidal water flux computed using volumetric-change method and index velocity method

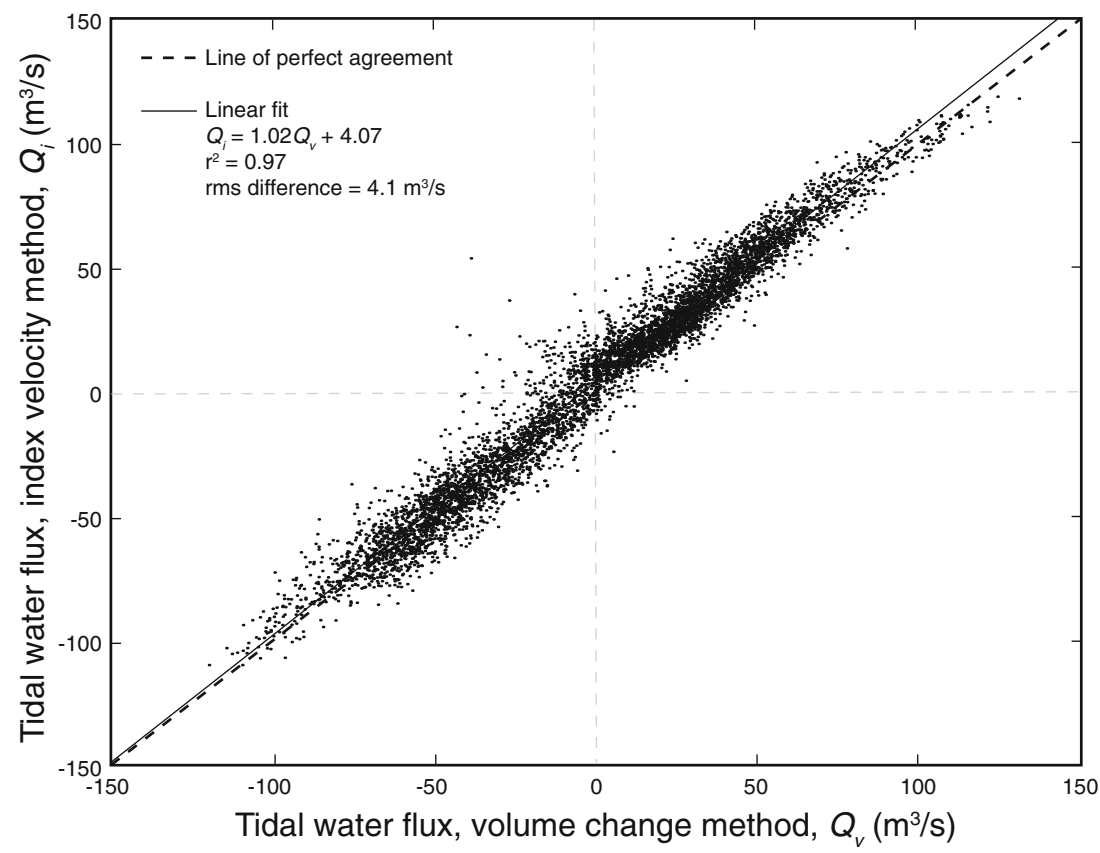


Fig. 6 Index salinity calibrations for sites Mouth and IMHJ

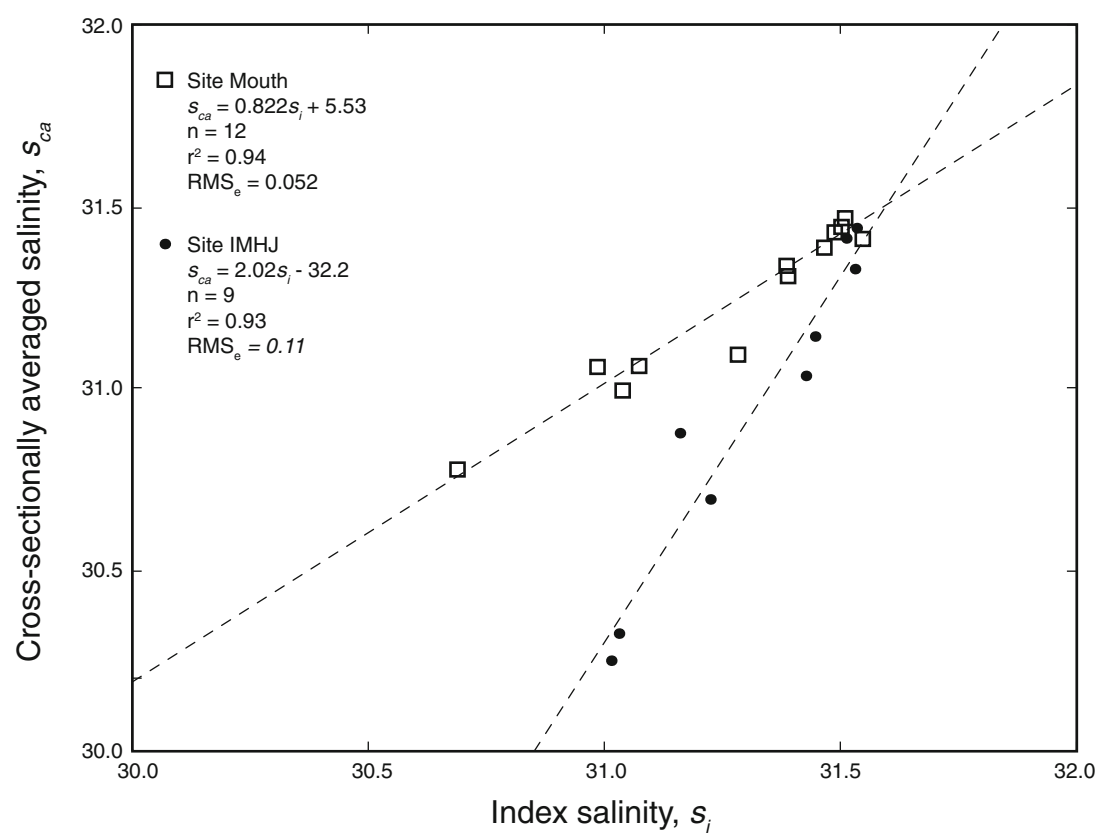

a $3 \%$ difference in mean freshwater flux and minimal difference in the time-varying signal. In comparison, Kroeger et al. (2006), using a watershed mass-balance analysis under annual precipitation conditions, estimated the total freshwater input to West Falmouth Harbor as $0.165 \mathrm{~m}^{3} / \mathrm{s}$. The TEF analysis, when applied over moving 120-h windows, yielded a time-varying signal that appears to correlate with the spring-neap signal (Fig. 4(E)). Variability was between 0.08 and $0.34 \mathrm{~m}^{3} / \mathrm{s}$ over the deployment period. In terms of the possible storage term (Eq. 8), a freshwater flux of $0.19 \mathrm{~m}^{3} / \mathrm{s}$ corresponds to a subtidal salinity change in the entire volume of the estuary of $0.6 \mathrm{psu} /$ day. We neglect the storage term presently due the difficulty of estimating salinity throughout the estuary; this is addressed in the discussion. The TEF quantities at site Mouth over the entire record were $Q_{\text {in }}=7.49 \mathrm{~m}^{3} / \mathrm{s}, Q_{\text {out }}=-7.68 \mathrm{~m}^{3} / \mathrm{s}, s_{\text {in }}=$ 31.4 , and $s_{\text {out }}=30.64$.

We estimated the mean freshwater flux at site IMHJ at $0.085 \mathrm{~m}^{3} / \mathrm{s}$ (half of the value estimated at site Mouth), with a spring-neap variability between less than 0 and $0.28 \mathrm{~m}^{3} / \mathrm{s}$ (Fig. 4). This is significantly lower that the expected value, based on the estimate by Kroeger et al. (2006). They estimated that only $7 \%$ of the total groundwater discharge occurs seaward of site IMHJ. It is likely that the calculated freshwater flux at site IMHJ is less reliable, due to the lateral and vertical variability of salinity, low quality of the salinity time series, and less accurate index-velocity relationship. Indeed, during the time frame of the tidal-cycle salinity surveys (when the index relationships are most accurate) the freshwater flux at sites Mouth and IMHJ compare well. The poorer agreement earlier in the record is likely the result of a non-stationary relationship between the index salinity and cross-sectionally averaged salinity.
Precipitation and Evaporation

Mean precipitation during the study period was $0.125 \mathrm{in} / \mathrm{d}$ or $0.026 \mathrm{~m}^{3} / \mathrm{s}$, which is $14 \%$ of the total freshwater flux. The precipitation rate is a source of freshwater to the estuary and should be subtracted from the calculated freshwater flux value to estimate the groundwater input. The mean evaporation over the deployment period was $0.048 \mathrm{~m}^{3} / \mathrm{s}$, with a range of $0.01-0.07 \mathrm{~m}^{3} / \mathrm{s}$. The evaporation rate is a "sink" of incoming groundwater, and should therefore be added to the freshwater flux value (minus precipitation) to yield groundwater input. The estimated groundwater input over the deployment period is therefore $0.21 \mathrm{~m}^{3} / \mathrm{s}$.

\section{Discussion}

Confirmation of Index Salinity Relationships and TEF Methodology: Numerical Simulations

Generating index-velocity/salinity calibrations in estuaries is complex due to reversing flow directions, stratification, and flood/ebb asymmetry in the cross-section. Additionally, application of the TEF method in a time-varying context using field data has not been tested in a modeling context. A hydrodynamic model can be used to estimate uncertainty in the calibrations by evaluating the modeled relationship between point index measurements (velocity or salinity) and the corresponding cross-sectionally averaged values over different time periods; the moving window TEF calculation can also be performed with model results to estimate the robustness of the method. In light of the apparent spring-neap signal in the data-based freshwater flux estimate, we used the model to corroborate 
the results based on data and discern if the spring-neap variation is real or an artifact of a time-varying index relationship and/or the TEF method. Due to the small effect of the indexvelocity relationship on estimated freshwater flux and the excellent comparison with the independent volumetric-change estimate, we focus here on the index-salinity relationship for sites Mouth and IMHJ.

We used the Regional Ocean Modeling System (ROMS) (Warner et al. 2008) on a $150 \times 200 \times 10$ cell domain, with $10-\mathrm{m}$ horizontal resolution and vertical resolution varying from 0.5 to $0.01 \mathrm{~m}$ (Fig. 7). Model options included wetting/drying of intertidal areas and radiation boundary conditions at the seaward boundary with Buzzards Bay conditions restored over a nudging timescale of $6 \mathrm{~h}$. This allowed for a delay in enforcing oceanic salinity as the tide turns from ebb to flood. Vertical mixing was parameterized with the $k-\varepsilon$ turbulence closure using the generic-length-scale method (Warner et al. 2005). Measured tidal water fluxes and water level were imposed at the seaward boundary, with a reference oceanic salinity of 32 psu. Freshwater point sources representing groundwater were distributed between six locations following Kroeger et al. (2006) (Fig. 7). Total freshwater input was held constant in time, with a total magnitude of $0.19 \mathrm{~m}^{3} / \mathrm{s}$ in accordance with the mean input determined from the measurements detailed above.
Near-bed salinity extracted from a model cell at the location of the index salinity measurement was compared with cross-sectionally averaged salinity on 9 August 2010 (Fig. 8), yielding a relationship similar to that obtained from vertical profiling on the same day (Fig. 6). This agreement indicates that the model's representation of lateral and vertical mixing processes in the channel during spring tides is, on average, correct. However, the model also shows that this relationship is not stationary: during neap tides (e.g., 3 August 2010) the slope and intercept change significantly, while the relationship over the entire time period differs only slightly from the spring tide relationship (Fig. 8). The change during neap tides is due to a doubling in vertical stratification (from $0.07 \mathrm{psu} / \mathrm{m}$ on spring tides to $0.16 \mathrm{psu} / \mathrm{m}$ on neap tides), leading to a different relationship between near-bed salinity and cross-sectionally averaged salinity. There is also significant hysteresis as the tide changes from flood to ebb (outliers in Fig. 8, neap tide regression). The same analysis at site IMHJ indicated that the index relationship was not stationary on the spring-neap timescale, though the discrepancy was less than at site Mouth. The index relationship extracted from the model during the period of vertical profiling (10 August 2010) did not match the field observations and indicated a laterally well-mixed
Fig. 7 ROMS model domain of West Falmouth Harbor. Blue arrows correspond to freshwater point sources. Intertidal areas (depth, $<0 \mathrm{~m}$, indicated by black contour) are activated when water level increases above critical value of $0.1 \mathrm{~m}$

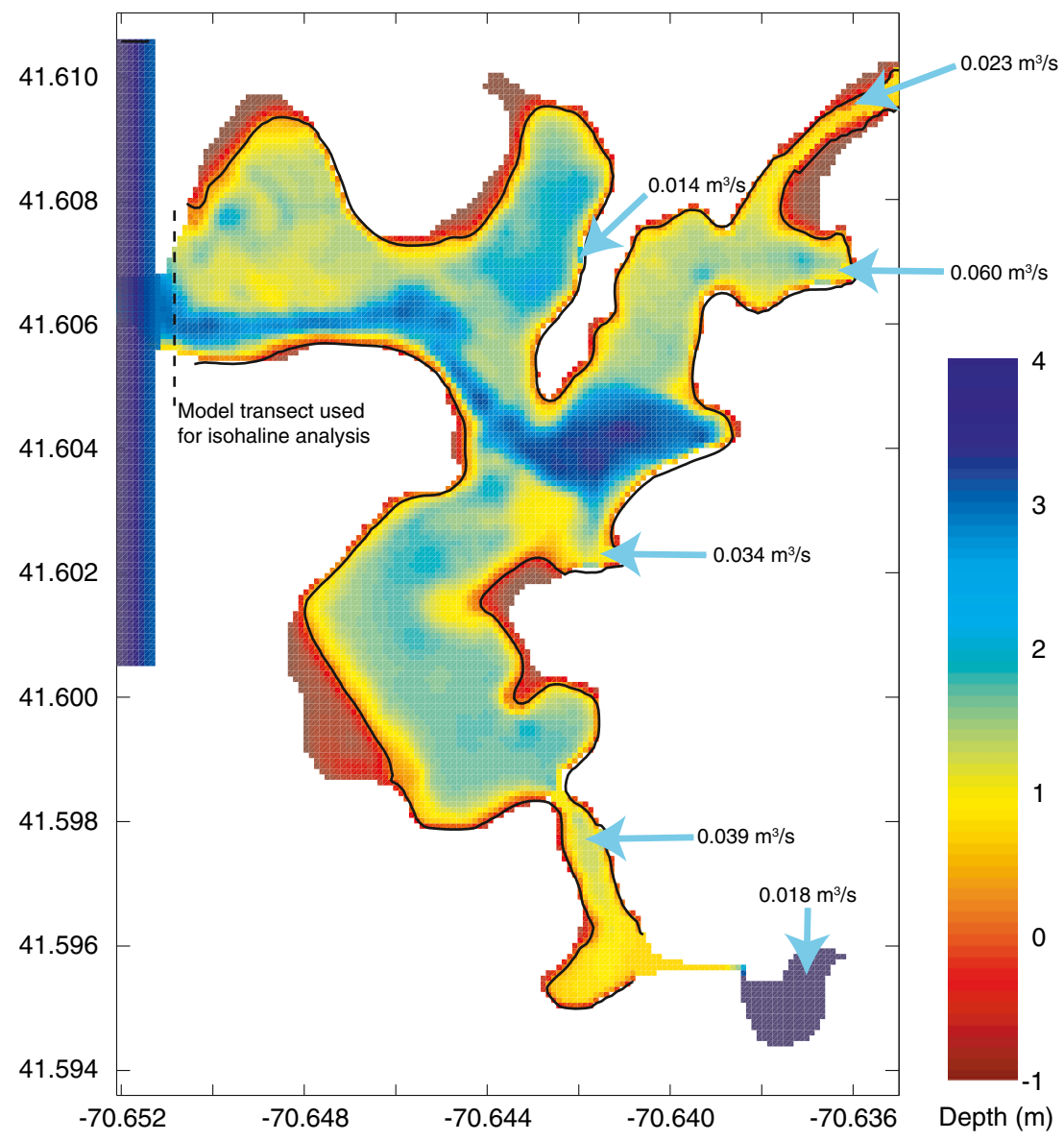


Fig. 8 Modeled index salinity relationships, correlating modeled near-bed salinity at site Mouth with modeled crosssectionally averaged salinity at harbor mouth. Linear regressions were applied to entire simulation, a tidal cycle during a spring tide period, and a tidal cycle during a neap tide period

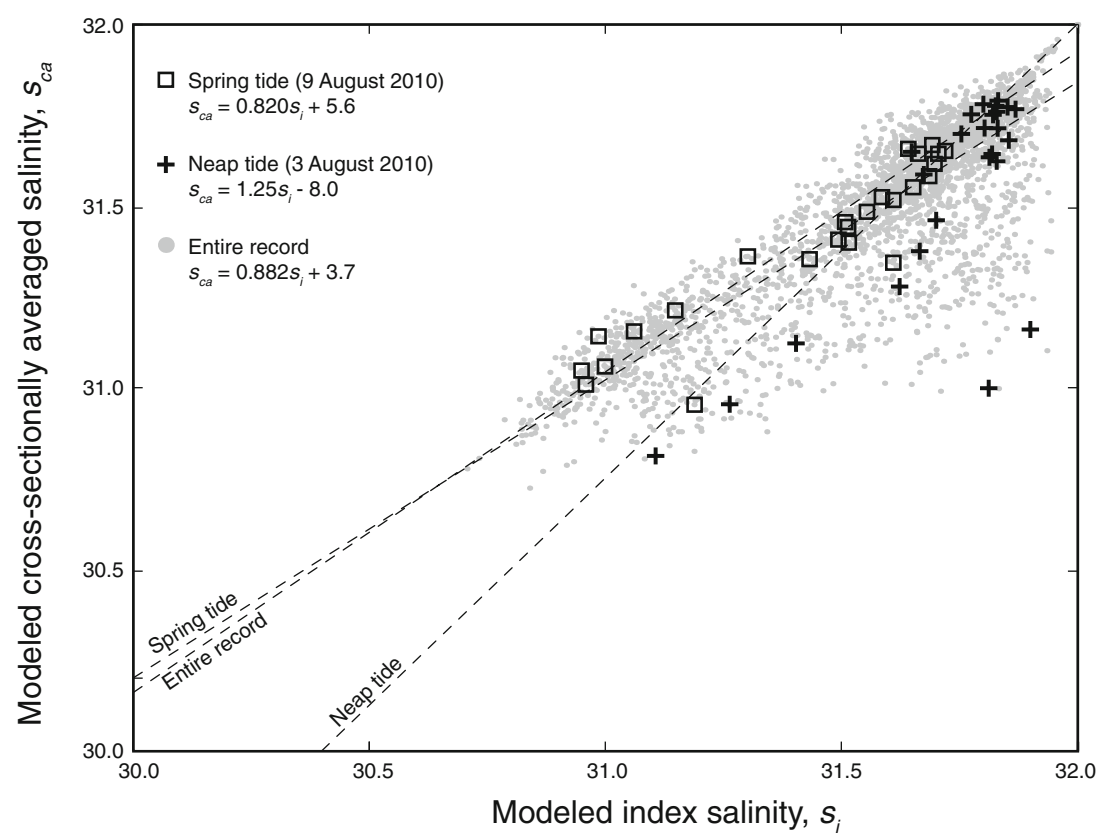

channel. This is likely due to the distribution of point sources in the model which are idealized and perhaps include disproportionately higher freshwater input to the southern half of the estuary, thereby leading to less crosssectional variability in the model as compared with the observations.

We applied the model-derived index-salinity relationships at site Mouth (spring, neap, and entire record) to the modeled index salinity to yield three hypothetical modeled cross-sectionally averaged salinity time-series. Freshwater flux was then computed for each case using the TEF method in a zero-dimensional context as was done with the field data (Fig. 9, middle tile) and compared with the modeled freshwater flux using a two-dimensional isohaline analysis that accounts for the entire cross-section (Fig. 9, upper tile). The accuracy of the TEF-derived outward freshwater flux can be checked by comparison with an "input-storage term", which in this case would be the constant modeled input $\left(0.19 \mathrm{~m}^{3} / \mathrm{s}\right)$ minus the salt storage term (last term on rhs of Eq. 8).

The comparison between the fully 2D TEF flux and the index-salinity derived flux suggests that most of the springneap variability in the observed freshwater flux time-series is actually an artifact caused by the use of a stationary index-salinity relationship. The use of the spring tide relationship, however, appears more suitable as it is more representative of average conditions in the channel than the neap tide relationship. The mean freshwater flux of the spring-tide-based result $\left(0.17 \mathrm{~m}^{3} / \mathrm{s}\right)$ is within $10 \%$ of the actual freshwater input $\left(0.19 \mathrm{~m}^{3} / \mathrm{s}\right)$. Therefore, even though the index-salinity relationship is temporally variable, the use of stationary index-salinity relationship (obtained during dominant conditions) may be suitable for deducing mean input over timescales longer than a spring-neap cycle (Fig. 9, lower tile). Practically, field observations over a few spring-neap cycles with cross-sectional measurements distributed over the period can be used to estimate the mean freshwater flux; a hydrodynamic model forced with this mean flux can then be implemented to gauge the timevarying flux due to storage or other mechanisms.

\section{Application of the TEF Method for Estimating Freshwater} Flux

The TEF method, combined with appropriate index relationships, presents an advance for the estimation of groundwater input to estuaries. When implemented at a seaward estuarine cross-section, this method integrates groundwater input along the interior shoreline. This is a valuable feature as groundwater input can often be spatially variable on the order of meters. Other methods such as eddy correlation (Crusius et al. 2008) or seepage meters (Lee 1977) may be more precise but are limited to a small footprint. Radiochemical tracers (Moore 1996; Cable et al. 1996) track water exported from coastal aquifers but encounter difficulty when attempting to separate the fresh fraction of groundwater from groundwater recirculated in the subterranean estuary.

The combination of high-temporal resolution velocity and salinity data makes the calculation of freshwater flux possible using the TEF method. The ability to extract the flux signal is due to the "amplification" of the groundwater signal by the tidal fluxes. If the tidal water fluxes entering and exiting the harbor entrance ceased, and the harbor entrance was essentially a river, it would be impossible to accurately measure a flux of $0.19 \mathrm{~m}^{3} / \mathrm{s}$ in a $200-\mathrm{m}^{2}$ channel using acoustic technology (a representative flow velocity of 



Fig. 9 Measured and modeled freshwater flux at harbor mouth, modeled input-storage term (upper), and measured and modeled freshwater flux using modeled index salinity relationships instead of full cross-sectional salinity distribution (middle), and measured and modeled freshwater flux with 28-d filter (lower)

$0.001 \mathrm{~m} / \mathrm{s}$ ). The standard deviation of a 1,200 kHz ADCP in the most accurate mode is about $0.004 \mathrm{~m} / \mathrm{s}$. However, in terms of salt the spring tide tidal prism of $1 \times 10^{6} \mathrm{~m}^{3}$ is diluted by $4 \times 10^{3} \mathrm{~m}^{3}$ of fresh groundwater over the same time frame (assuming complete mixing). This leads to a $0.4 \%$ dilution of 32 psu water, or 0.13 . Modern salinity sensors can easily detect this deviation with high accuracy $(0.003 \mathrm{mS} / \mathrm{cm}$; or about $0.002 \mathrm{psu})$. Therefore, while acoustic velocity sensors cannot capture residual velocities due to groundwater fluxes, salinity sensors can easily measure the small addition of freshwater to the tidal salt fluxes.

\section{Assessing Suitability of Methodology}

The field and modeling studies enable us to speculate on the suitability of these methods in estuaries. Well-mixed estuaries with large river inputs relative to groundwater may provide an excellent testing ground for the method, due to the ease of measuring unidirectional river flow at the landward end of the estuary. Estuaries with dominant groundwater inputs are ideal candidates due to the general difficulty of estimating coastal groundwater discharge. The amplification of the groundwater signal is performed by the tides, therefore ideal sites will have sufficient flood tidal prism to mix estuarine/oceanic water with freshwater and exit with a modified salinity that is detectable by sensors. Within the cross-section of interest, it is critical that the channel is relatively well mixed. Variations in lateral and vertical structure are inevitable, and therefore it is necessary to estimate the variability as often as possible over spring and neap tides. The index-salinity method is most likely to work in well-mixed estuarine channels and least likely to work in channels with strong gravitational circulation, due to spatial correlations between velocity and salinity which are difficult to estimate over extended time periods in the entire cross-section. Stratified cross-sections would require some vertical resolution of the velocity and salinity profiles in order to generate index relationships in segments of the cross-section over various tidal conditions.

Identifying the vertical structure of salinity in a particular cross-section can be based on the horizontal Richardson 
number. This dimensionless quantity gives an indication of the vertical mixing in an estuary (MacCready and Geyer 2010), defined as:

$R i_{\mathrm{x}}=\frac{\beta g s_{\mathrm{x}} H^{2}}{u_{*}^{2}}$

where $\beta$ is $7.7 \times 10^{-4} \mathrm{psu}^{-1}, s_{\mathrm{x}}$ is the longitudinal salinity gradient, $H$ is the water depth in the thalweg, and $u_{*}{ }^{2}$ is the friction velocity at maximum depth-averaged tidal velocity (computed here assuming a logarithmic velocity profile). Here we use model results for the salinity structure and velocity to estimate $R i_{\mathrm{x}}$ over spring and neap tides. At site Mouth, $R i_{\mathrm{x}}$ varies between 0.07 and 0.55 , while at site IMHJ $R i_{\mathrm{x}}$ varies between 0.39 and 1.0. These results are congruent with the vertical profiling which indicated that stratification at site IMHJ was twice that at site Mouth. This further reinforces the importance of site selection for development of index salinity relationships: sites with relatively larger $R i_{\mathrm{x}}$ may be unsuitable.

\section{Observational Error}

Apart from error in the index salinity relationship, the observational estimate of freshwater flux is most sensitive to possible temporal bias in salinity. A bias in the index salinity relationship on a certain phase of the tide would skew the computation of transport in salinity space used in the TEF calculation. For example, applying a bias of \pm 0.05 psu (error in index salinity measurement) on ebb tides skews $Q_{\mathrm{R}}$ by $\pm 0.03 \mathrm{~m}^{3} / \mathrm{s}$, or $16 \%$. The TEF calculation appears to be largely insensitive to small differences in tidal water flux between the various methods (index-velocity linear, indexvelocity quadratic, and volumetric change). We also applied a general error propagation analysis (Taylor 1997) to the observational data used in Eq. 8, yielding an error of $0.025 \mathrm{~m}^{3} / \mathrm{s}$. We applied the index-velocity RMS error (Fig. 5), index-salinity RMS error for site Mouth (Fig. 6), and a $2 \%$ cross-sectional area measurement error (Ganju et al. 2005) to computed values of $\Delta s, s_{\text {out }}$, and $Q_{\text {in }}$ for the entire period of record.

\section{Conclusions}

We estimated fresh coastal groundwater discharge to West Falmouth Harbor, Massachusetts, using tidal water flux and salinity measurements at the harbor mouth, in combination with a TEF salt balance calculation. Tidal water flux and cross-sectionally averaged salinity were estimated over an 8week period using correlations between point (index) and cross-sectional measurements through tidal-cycle observations. The mean freshwater input ostensibly due to groundwater discharge over the 8 -week period was $0.21 \pm 0.025 \mathrm{~m}^{3} / \mathrm{s}$ which compares well with the long-term watershed mass-balance estimate of $0.165 \mathrm{~m}^{3} / \mathrm{s}$ (Kroeger et al. 2006). Measurement of the groundwater discharge through a salt balance is possible because the tidal water fluxes and TEF method amplify the relatively small freshwater signal, and salinity sensors can measure this dilution of salt water with high accuracy. However, comparison of two sites along the axis of the harbor indicated that freshwater flux estimates were sensitive to the index salinity relationship. Further investigation comparing field data to model simulations demonstrated that spring-neap timescale variations in the index-salinity relationship resulted in unrealistic spring-neap variations in freshwater flux estimates from field observations. As a result, we recommend averaging over at least spring-neap timescales to derive mean fresh water flux. Both the observational and numerical methods implemented here can be used in succession to estimate the mean freshwater flux. Tidal water flux and salinity measurements over sufficiently long periods ( $>2$ weeks) combined with TEF calculations yield a first approximation of the mean freshwater flux; a three-dimensional hydrodynamic model forced with that flux can then diagnose the time-varying nature of the signal and possible shortcomings of the observational data.

Acknowledgments Funding was provided by the USGS Coastal and Marine Geology Program and by National Science Foundation Award \#0420575 from the Biocomplexity/Coupled Biogeochemical Cycles Program. Access to private property was granted by Alan Rottenberg, Michael Jackson, and Jonathan Harley. Jonathan Borden, Jennifer Thomas, Lane Boyer, and Alex Nunez performed tidal-cycle surveys with support from Marinna Martini and Christine Sabens. Rocky Geyer, Kevin Kroeger, David Ralston, Christopher Sherwood, Richard Signell, John Warner, and two anonymous reviewers provided feedback on this study and/or manuscript. Any use of trade, product, or firm names is for descriptive purposes only and does not imply endorsement by the U.S. Government.

\section{References}

Boesch, D.F. 2002. Challenges and opportunities for science in reducing nutrient over-enrichment of coastal ecosystems. Estuaries 25: 744-758.

Bricker, S., Longstaff, B., Dennison, W., Jones, A., Boicourt, K., Wicks, C., and Woerner, J., 2007. Effects of nutrient enrichment in the nation's estuaries: a decade of change. NOAA Coastal Ocean Program Decision Analysis Series No. 26. National Centers for Coastal Ocean Science, Silver Spring, MD.

Cable, J.E., W.C. Burnett, J.P. Chanton, and G.L. Weatherly. 1996. Estimating groundwater discharge into the northeastern Gulf of Mexico using radon-222. Earth and Planetary Science Letters 144: 591-604.

Costa, J.E., R.T. Cheng, F.P. Haeni, N. Melcher, K.R. Spicer, E. Hayes, W. Plant, K. Hayes, C. Teague, and D. Barrick. 2006. Use of radars to monitor stream discharge by noncontact methods. Water Resources Research 42: W07422. doi:10.1029/2005WR004430.

Crusius, J., P. Berg, D.J. Koopmans, and L. Erban. 2008. Eddy correlation measurements of submarine groundwater discharge. Marine Chemistry 109: 77-85. 
Dunne, T., and L.B. Leopold. 1978. Water in environmental planning, 95-119. New York: W.H. Freeman and Company.

Ganju, N.K. 2011. A novel approach for direct estimation of fresh groundwater discharge to an estuary. Geophysical Research Letters 38: L11402.

Ganju, N.K., and D.H. Schoellhamer. 2006. Annual sediment flux estimates in a tidal strait using surrogate measurements. Estuarine, Coastal and Shelf Science 69: 165-178.

Ganju, N.K., D.H. Schoellhamer, and B.A. Bergamaschi. 2005. Suspended sediment fluxes in a tidal wetland: Measurement, controlling factors, and error analysis. Estuaries 28: 812-822.

Ganju, N.K., Dickhudt, P.J., Thomas, J.A., Borden, J., Sherwood, C.R., Montgomery, E.T., Twomey, E.R., and Martini, M.A., 2011, Summary of oceanographic and water-quality measurements in West Falmouth Harbor and Buzzards Bay, Massachusetts, 2009_ 2010: Open-File Report 2011-1113, CD-ROM. Also available at http://pubs.usgs.gov/of/2011/1113/.

Howarth, R.W. 2008. Coastal nitrogen pollution: A review of sources and trends globally and regionally. Harmful Algae 8: 14-20.

Howes, B., Kelley, S.W., Ramsey, J.S., Samimy, R., Schlezinger, D., and Eichner, E., 2006. Linked watershed-embayment model to determine critical nitrogen loading thresholds for West Falmouth Harbor, Falmouth, Massachusetts. Massachusetts Estuaries Project: Massachusetts Department of Environmental Protection, Boston, Massachusetts, $161 \mathrm{p}$.

Knudsen, M. 1900. Eine hydrographische Lehrsatz. Annalen der Hydrographie und Marinen Meteorologie 28: 316-320.

Kroeger, K.D., M.L. Cole, J.K. York, and I. Valiela. 2006. Nitrogen loads to estuaries from waste water plumes: modeling and isotopic approaches. Groundwater 44: 188-200.

Kroeger, K.D., P.W. Swarzenski, W.J. Greenwood, and C. Reich. 2007. Submarine groundwater discharge to Tampa Bay: Nutrient fluxes and biogeochemistry of the coastal aquifer. Marine Chemistry 104: 85-97.

LeBlanc, D.R., Guswa, J.H., Frimpter, M.H., and Londquist, C.J., 1986. Ground-water resources of Cape Cod, Massachussetts. U.S. Geological Survey Hydrologic Atlas 692.

Lee, D.R. 1977. A device for measuring seepage flux in lakes and estuaries. Limnology and Oceanography 22: 140-147.

MacCready, P. 2011. Calculating estuarine exchange flow using isohaline coordinates. Journal of Physical Oceanography 41: 11161124.

MacCready, P., and W.R. Geyer. 2010. Advances in estuarine physics. Annual Reviews of Marine Science 2: 35-58.

McGlathery, K.J., K. Sundback, and I.C. Anderson. 2007. Eutrophication in shallow coastal bays and lagoons: The role of plants in the coastal filter. Marine Ecological Progress Series 348: 1-18.

Moore, W.S. 1996. Large groundwater inputs to coastal waters revealed by ${ }^{226} \mathrm{Ra}$ enrichments. Nature 380: 612-614.
Mueller, D.S., and Wagner, C.R., 2009. Measuring discharge with acoustic Doppler current profilers from a moving boat. U.S. Geological Survey Techniques and Methods 3A-22, $72 \mathrm{p}$.

National Research Council. 2000. Clean coastal waters: Understanding and reducing the effects of nutrient pollution, 391. Washington: National Academy Press.

Nixon, S.W., B. Buckley, S. Granger, and J. Bintz. 2001. Responses of very shallow marine ecosystems to nutrient enrichment. Human and Ecological Risk Assessment 7: 1457-1481.

Pawlowicz, R., B. Beardsley, and S. Lentz. 2002. Classical tidal harmonic analysis including error estimates in MATLAB using T_TIDE. Computers \& Geosciences 28: 929-937.

Penman, H.L. 1948. Natural evaporation from open water, bare and grass. Proceedings of the Royal Society of London, Ser. A 193: $120-145$.

Portnoy, J.W., B.L. Nowicki, C.T. Roman, and D.W. Urish. 1998. The discharge of nitrate-contaminated groundwater from developed shoreline to marsh-fringed estuary. Water Resources Research 34: 3095-3104.

Ruhl, C.A., and Simpson, M.R., 2005. Computation of discharge using the index-velocity method in tidally affected areas. U.S. Geological Survey Scientific Investigations Report 2005-5004. Available at http://pubs.usgs.gov/sir/2005/5004.

Shuttleworth, W.J. 1993. Evaporation. In Handbook of hydrology, ed. D.R. Maidment, 4.1-4.53. New York: McGraw-Hill.

Simpson, M.R., and R. Bland. 2000. Methods for accurate estimation of net discharge in a tidal channel. Institute of Electrical and Electronics Engineers Journal of Oceanic Engineering 25: 437445.

Simpson, M.R., and Oltmann, R.N., 1993. Discharge-measurement system using an acoustic Doppler current profiler with applications to large rivers and estuaries. U.S. Geological Survey Water-Supply Paper 2395, 32 p. Available at http://pubs.usgs.gov/wsp/wsp2395.

Taylor, J.R. 1997. An introduction to error analysis, 2nd ed. Sausalito: University Science.

Valiela, I., J. Costa, K. Foreman, J.M. Teal, B. Howes, and D. Aubrey. 1990. Transport of groundwater-borne nutrients from watersheds and their effects on coastal waters. Biogeochemistry 10: 177-197.

Wagner, R.J, Boulger, R.W., Jr., Oblinger, C.J., and Smith, B.A., 2006. Guidelines and standard procedures for continuous water-quality monitors: station operation, record computation, and data reporting. U.S. Geological Survey Techniques and Methods 1-D3, 51 p.

Warner, J.C., C.R. Sherwood, H.G. Arango, and R.P. Signell. 2005. Performance of four turbulence closure models implemented using a generic length scale method. Ocean Modelling 8: 81-113.

Warner, J.C., C.R. Sherwood, R.P. Signell, C.K. Harris, and H.G. Arango. 2008. Development of a three-dimensional, regional, coupled wave, current, and sediment-transport model. Computers \& Geosciences 34: 1284-1306. 